FOR THE RECORD

\section{Fallen MAPLEs}

$\mathrm{P}$ ersistent technical problems and "economic impediments" have sunk the over budget, overdue and overdesigned Multipurpose Applied Physics Lattice Experiment (MAPLE) reactors, long touted as the future jewel of Canadian medical isotope supply.

Atomic Energy of Canada Ltd. announced May I6, 2008, that it was pulling the plug on the troubled reactors (CMAJ 2008;178[7]:813-4) and will instead seek to extend the lifetime of Canada's 5I-year-old National Research Universal reactor to ensure national supply of medical isotopes.

Hugh MacDiarmid, president and chief executive officer of the federal Crown corporation, cast the decision as necessary, stating that "it is no longer feasible to complete the commissioning and start-up of the reactors."

Federal Minister of Natural Resources Gary Lunn said a dozen years of redesign had failed to generate a single isotope. "The project has long been crippled by both technical and economic impediments, which remained unresolved.
Among the many factors are: regulatory challenges and commercial disputes which so far have cost hundreds of millions of dollars in private and public funds; technical malfunctions that could not be resolved; and reviews conducted by the Auditor General which revealed significant concerns about the costs, the delays, and the technical issues."

As reported earlier in $C M A J$, total costs to date for the MAPLEs project have easily topped $\$ 500$ million (although precise outlays have never been disclosed), and the agency has been entirely perplexed by a fundamental design flaw that invariably generated unexpected positive power coefficient reactivity in operational tests.

Lunn said the government has asked Atomic Energy of Canada Ltd. to seek an extension of the aging National Research Universal reactor's operating site licence beyond Oct. 3I, 20II, to ensure isotope supply. That, in turn, prompted the Canadian Association of Nuclear Medicine to call for the development of a contingency plan in the the event the reactor is again shutdown for reasons of safety or maintenance.

The lack of contingency planning and Canadian isotope distributor MDS Nor-

\title{
Onward and upward
}

$\mathrm{D}$ rug spending in Canada is rising faster than overall health spending and easily outstripping the rate of inflation, according to the Canadian Institute of Health Information's annual drug spending report.

Canadian outlays for drugs topped $\$ 27$-billion in 2007, an increase of $\$ 2$ billion or roughly $7.2 \%$ over 2006 . Spending on prescription drugs rose $7.5 \%$ to $\$ 22.5$ billion and now constitutes $83.6 \%$ of the overall drug bill. Outlays for nonprescription drugs (over-the-counter drugs and personal health supplies like disposable diabetic syringes) rose $7.5 \%$ to $\$ 22.5$ billion.

Per capita drug spending by Canadians was pegged at $\$ 818$ in 2007 , and drugs now consume $16.8 \%$ of the health care pie. The study also indicated there is a significant regional variation in per capita drug outlays, ranging from lows of $\$ 660$ in British Columbia and \$710 in Manitoba, to highs of \$878 in Ontario and \$910 in New Brunswick. "These variations may be influenced by a number of factors, including differences in public and private drug programs, approaches to generic drug substitution, health care delivery and disease patterns, as well as differences in the age and sex distributions across the provinces," states the Institute's Manager of Pharmaceutical Programs Michael Hunt.

The statistics also indicate that as of 2005, Canada had the second-highest level of total per capita drug spending (\$735) among Organization for Economic Co-operation and Development nations. Only the United States, at $\$ 988$ per capita, had a higher rate. Canada's public share of total drug spending, at $38.7 \%$, fell well below the OECD median of $64.5 \%$. - Wayne Kondro, CMAJ

dion's disdain for international efforts aimed at developing a global isotope contingency plan were the subject of several $C M A J$ news articles $(C M A J$ 2008;178 [5]:536-8 and $C M A J$ 2008;178[6]:668), which prompted parliamentarians to earlier this year request that $C M A J$ staff appear before Commons committees.

With the MAPLEs having been cancelled and the Auditor General of Canada having estimated it will take at least $\$ 600$ million to refurbish the Chalk River site where the national reactor is located, the question of long-term continuity of supply becomes a critical issue. But Atomic Energy of Canada Ltd. has offered no hint whether it will launch an exercise to design an alternative to the MAPLEs.

\section{Nursing “misadventures"}

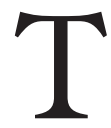
here's a $I$ in 5 chance that a hospital patient will be administered the wrong dose of a drug, according to a Statistics Canada survey of the nation's nurses.

Medication errors are most commonly made by nurses working overtime, with $22 \%$ indicating that they'd either "occasionally" or "frequently" administered the wrong drug to a patient while putting in extra hours, according to the "Correlates of medication error in hospitals" report. By comparison, some I $4 \%$ of nurses admitted to medication errors made while not working overtime.

The findings are based on data culled from the 2005 National Survey of the Work and Health of Nurses, which conducted telephone interviews with nurses on condition of confidentiality.

The study found that nurses working I2-hour shifts are less likely (I8\%) to make medication errors than nurses working 8 -hour shifts $(22 \%)$. There was less statistical variation for other factors such as hours of work per week, full-time versus part-time employment, and day or night shifts.

The nurses attributed the cause of the medication errors to excessive workload, "poor" relations with the attending physicians, work stress or lack of support from coworkers. - Wayne Kondro, CMAJ

DOI:Io.I503/cmaj.080788 